\title{
Synthesis of sulfonated Sesamum indicum L. seed oil and its application as a fatliquor in leather processing
}

\author{
Adachukwu N. Nkwor ${ }^{1 *}$ D, Pius O. Ukoha² and Ikhazuagbe H. Ifijen ${ }^{3}$
}

\begin{abstract}
Fatliquor is an oil-in-water emulsion that improves the physical properties of leather such as tensile strength, flexibility, and softness by lubricating the leather fibres. Sulfonated Sesamum indicum oil was synthesized, characterized, and examined for consideration as a substitute for imported fatliquor in Nigeria. The sulfonation of the oil was confirmed by the significant observations made in the FTIR, ${ }^{1} \mathrm{H} \mathrm{NMR},{ }^{13} \mathrm{C} N M \mathrm{R}$, and ${ }^{13} \mathrm{C}$ NMR DEPT analysis results. A remarkable difference was observed in the physicochemical properties results of both unsulfonated and sulfonated oils. The sulfonated sesame fatliquor was applied onto goatskin and compared with a commercial sulfated fatliquor in the processing of shoe upper leather using standard methods. The average results for tensile strength, double edge tear, elongation, and softness results for the commercial and synthesized fatliquors are as follows: $14.27 \mathrm{~N} / \mathrm{mm}^{2} ; 13.77 \mathrm{~N} / \mathrm{mm}^{2}, 50.61 \mathrm{~N} ; 60.11 \mathrm{~N}, 38.06 \% ; 54.28 \%, 25.2 ; 25.0$. A comparable level of lubrication of the leather treated with the sulfonated Sesamum indicum oil and that treated with the commercial leather fatliquor was revealed by the Sudan IV stain test as well as scanning electron microscopy analysis results. Experimental analyses, therefore, show that the as-synthesized sulfonated Sesamum indicum oil could be considered as a substitute for imported fatliquor in the leather industry.
\end{abstract}

Keywords: Characterisation, Fatliquor, Leather, Sesamum indicum, Sulfonation, Vegetable oil

\section{Introduction}

The leather making process brings about the transformation of hides and skin into leather via several chemical and mechanical steps such as soaking, unhairing/liming, deliming/bating, pickling, tanning, neutralization/dyeing, fatliquoring, drying, and finishing. Natural oil, which is a vital component that brings about strength, flexibility, and softness in the skins/hides of animals is usually lost during the pretanning operations. This is necessary to aid the penetration of water-soluble chemicals into the hide - a requirement for an effective tanning process. During the tanning operation, the purified matrix is modified

\footnotetext{
* Correspondence: adachukwu.nkwor@funai.edu.ng; adannkwor@yahoo.com 'Department of Chemistry/Biochemistry/Molecular Biology, Alex Ekwueme Federal University Ndufu-Alike Ikwo, P.M.B 1010, Abakaliki, Ebonyi State, Nigeria

Full list of author information is available at the end of the article
}

by chrome tanning agents, vegetable tannins, or syntans into a durable non-putrescible substrate [1]. If leather processing is completed without reintroducing oil after tanning, the leather product becomes rigid, difficult for use in the manufacture of leather products. The fatliquoring step of leather processing, therefore, becomes necessary as fatliquor replaces the natural oils previously removed while ensuring an effective leather tanning. These oil replacements (fatliquors) which are polar often include modified vegetable oils $[2,3]$ modified animal oils [4], synthetic oils, or oils mixed with emulsifiers [5].

Sulfonation of vegetable oils entails the modification of vegetable oils whereby sulfuric acid reacts with the unsaturated fatty acids at low temperatures. It introduces the hydrophilic group to the long hydrophobic carbon chains of the vegetable oils by entering into the double
Springer Open which permits use, sharing, adaptation, distribution and reproduction in any medium or format, as long as you give appropriate credit to the original author(s) and the source, provide a link to the Creative Commons licence, and indicate if changes were made. The images or other third party material in this article are included in the article's Creative Commons licence, unless indicated otherwise in a credit line to the material. If material is not included in the article's Creative Commons licence and your intended use is not permitted by statutory regulation or exceeds the permitted use, you will need to obtain permission directly from the copyright holder. To view a copy of this licence, visit http://creativecommons.org/licenses/by/4.0/. 
bonds. This is then followed by neutralization with alkali. The sulfonated oil obtained can readily form an emulsion in water. The introduction of the sulfonated oil into the collagen fibres usually leads to their lubrication without leaving an oily feel on the surface of the leather $[1,6]$.

In this study, the method of sulfonation used does not involve washing with water or aqueous solutions and results in the manufacture of sulfonated products with negligible inorganic salt content and also does not form hydrolytic by-products [7]. This is quite unlike some sulfonation processes earlier reported $[8,9]$. The inorganic salt content reduces the stability of emulsions produced with the sulfonated oils and is often detrimental to the leather processed with such sulfonated oils. The hydrolytic by-products give haziness to the finished oil, cause it to be unstable, separate on storage, and accelerate the oxidation of the oil. Non-sustainable oils like whale oils and synthetic oils are the dominant oils for fatliquor manufacture and these have their obvious disadvantages.

For this study, our focus is on Sesamum indicum from the Pedaliaceae family. It is an annual oilseed crop cultivated in both tropics and temperate zones of the world [10]. Sesame seed has been reported to contain a high level of unsaturated fatty acids which are oleic acid, $38.86 \%$, and linoleic acid, $46.18 \%$ [11]. However, the fatty acid composition of vegetable oils varies and is dependent on several parameters such as extraction process, seed variety, climatic condition, the extent of fruit ripening, harvesting period, and harvesting technique [12-14]. This edible oil has been grown from ancient times as a cooking oil and flavour enhancer in many continental and intercontinental dishes [15].

Despite the numerous uses of this annual crop, industrial and domestic utilization have not been fully developed in Nigeria. The need to utilize this abundant crop in solving the nation's industrial need is very essential hence; this study evaluated the possibility of using fatliquor made from sesame seed oil in the fatliquoring of light leather. The effectiveness of the prepared fatliquor on light leather has also been compared with an imported sulfated fatliquor commonly used in Nigerian tanneries. The use of sesame oil to synthesize fatliquor ensures a significant cut in import cost. This study, therefore, proposes the use of sulfonated sesame oil as a substitute for imported fatliquor in the Nigerian leather industry, thereby turning an under-utilized seed into a highly valuable product.

\section{Materials and methods}

\subsection{Materials}

Dry capsules of matured (S. indicum) seeds were harvested from a local farm at Noyo, Ikwo, Ebonyi State. Chrome tanned goatskin (Wet blue goatskin) was obtained from the tannery at the Institute for Creative Leather Technologies (ICLT), The University of Northampton (UoN), Northampton, United Kingdom. Reagents used in the laboratory for extraction, synthesis, and analysis were of analytical grade whereas those used for leather processing were of commercial/industrial grade.

\subsection{Sample seed preparation}

Sample seeds were identified in the Department of Biological Sciences, Ahmadu Bello University Zaria, Nigeria. The voucher sample was kept and voucher no was given. These dry seeds were then cleaned, dehulled, washed, and sundried to reduce the moisture content before being crushed (approximately $2 \mathrm{~mm}$ ) using a hand grinding machine).

\subsection{Extraction of Sesamum indicum oil}

Soxhlet extraction of the ground seeds was done in a Soxhlet apparatus using n-hexane (Sigma Aldrich) as a solvent. S. indicum seeds were dried in an oven at $40^{\circ} \mathrm{C}$ for $5 \mathrm{~h}$. One hundred grams of the ground seeds were transferred into a thimble and the oil extracted using $n$ hexane as a solvent with the aid of a Soxhlet-apparatus for $4 \mathrm{~h}$. The solvent was recovered in the in-built capacity in the Soxhlet extractor leaving the oil sample for analysis. The process of extraction was repeated until a sufficient quantity of the oil was obtained.

\subsection{Sulfonation reaction procedure}

The formation of sulfonated oil from fatty acids and sulfuric acid was carried out according to a published procedure [16]. Concentrated sulfuric acid $(45 \mathrm{~mL}$ ) (Sigma Aldrich) was added dropwise into a beaker containing $150 \mathrm{~g}$ of Sesamum indicum oil (being constantly stirred at $20^{\circ} \mathrm{C}$ for $2 \mathrm{~h}$ ). The mass obtained after the treatment of the fatty acid with the Sesamum indicum oil was dissolved in $450 \mathrm{~mL}$ of ethanol (Sigma Aldrich) and neutralized using 15\% NaOH (Sigma Aldrich) (dissolved in methanol). The salt was filtered off under vacuum. The solvent was removed and recovered with the aid of a rotary evaporator to obtain the resulting sulfonated oil.

\subsection{Characterizations of $S$. indicum oil}

Physicochemical properties of $S$. indicum oil were determined according to the methods recommended by the Society of Leather Chemists and Technologists [17]. The fatty acid composition of the oil was obtained using an Agilent19091S-433HP-5MS gas chromatograph attached to a mass spectrometer. For this purpose, the oil was methylated using a method described by Adewuyi et al [18]. The injection and detection temperatures for the gas chromatograph were 280 and $300{ }^{\circ} \mathrm{C}$ respectively. Helium was used as the carrier gas at a flow rate of $20 \mathrm{~mL} / \mathrm{min}$. The area 
percentages were recorded with a standard Chemstation Data system. For the mass spectrometry, an ACQ mode scanner (with a scan range of 15-500 amu and voltage of 2094) was used and the mass spectra were compared with the NIST11 mass spectral library.

To determine the $\% \mathrm{SO}_{3}$ of the sulfonated oil (SLC 318), $4 \mathrm{~g}$ of sulfonated $S$. indicum oil was weighed into a one litre volumetric flask. It was dissolved in distilled water and made up to the volume. The solution $(10 \mathrm{~mL})$ was pipetted into a $100 \mathrm{~mL}$ stoppered cylinder. Chloroform, $15 \mathrm{~mL}$, was added to the solution in the stoppered cylinder. Methylene blue indicator $(25 \mathrm{~mL})$, was also added and shaken thoroughly. The resulting mixture was then titrated with $0.0025 \mathrm{M}$ Cetyl trimethyl ammonium bromide (CTAB) (Sigma-Aldrich) with frequent shaking until, on allowing the solution to settle, the colour intensity of the two layers becomes the same. The value for $\% \mathrm{SO}_{3}$ is twice titre divided by the mass of sulfonated oil taken $[17,19]$.

The thermal properties of the unsulfonated and sulfonated $S$. indicum oils were determined using a differential scanning calorimeter (DSC 2 Star System (Mettler Toledo)). Nitrogen, used as a purge gas had a flow rate of $\sim 60 \mathrm{~mL} / \mathrm{min}$. Samples of oil, of between 5 and 7 mg, were weighed into low-pressure aluminum crucibles and sealed hermetically. The sealed crucibles were pierced before the analysis. An empty, hermetically sealed aluminum crucible with a pinhole was used as a reference. A temperature profile of -80 to $180^{\circ} \mathrm{C}$ was run using the following temperature program: $-80^{\circ} \mathrm{C}$ isotherm for $3 \mathrm{~min}$; dynamic ramp at $-80^{\circ} \mathrm{C}$ to $180^{\circ} \mathrm{C}$ (at $10^{\circ} \mathrm{C} \mathrm{min}{ }^{-1}$ ), isotherm at $180{ }^{\circ} \mathrm{C}$ for $3 \mathrm{~min}$; isotherm at $30^{\circ} \mathrm{C}$ for $2 \mathrm{~min}$. The subsequent DSC data was examined for peak temperature, onset temperature, and melting temperature for comparison. The DSC tests were done in triplicate and average values stated. The temperature at the melting transition (End set) was used as the melting temperature [20]. The modification of the $S$. indicum oil was investigated by the FT-IR measurement $\left(600-4000 \mathrm{~cm}^{-1}\right)$ of both the virgin and modified oil using a Shimadzu 8400S FT-IR instrument (Shimadzu, Milton Keynes, UK). To investigate the presence of $\mathrm{H}-\mathrm{C}-\mathrm{S}$ and $\mathrm{H}-\mathrm{C}-\mathrm{O}-\mathrm{S}$ group in the modified oil, ${ }^{1} \mathrm{H}$ NMR and ${ }^{13} \mathrm{C}$ NMR spectra of both the virgin and modified oil were acquired on a Bruker Bruker Biospin AV500 - $5 \mathrm{~mm}$ BBO probe with Z-axis gradient, TOPSIN v 2.1, ${ }^{1} \mathrm{H}=500.13 \mathrm{MHz},{ }^{13} \mathrm{C}=125.76 \mathrm{MHz}$ (Brucker, Coventry, UK).

\subsection{Leather shoe upper manufacturing process}

Wet blue goatskin, shaved at $1.2-1.3 \mathrm{~mm}$ was divided into two halves from the backbone such that the sampling positions in the butt area [21] were uniformly represented in the halves.

A conventional shoe upper manufacturing process [22] was used. In this process, for adequate comparison, the right half of the goatskin was processed with sulfonated S. indicum oil (SSO) whereas the left half was processed with the commercial sulfated fatliquor, Trupon DXV (TrumplerGmbh, Worms, Germany) which is also the positive control, PC. Using two separate tanning drums, the two halves were processed as leather shoe uppers. Dyeing process was however omitted in both drums so that the sudan stain test could be effectively done and the necessary colour observations made. Table 1 shows the fatliquoring process for shoe upper leather manufacture [22].

\subsection{Strength/mechanical/physical properties of the shoe upper leathers}

The trial leather samples, PC and SSO were conditioned for $48 \mathrm{~h}$ using the British standard procedure $\left(20^{\circ} \mathrm{C}, \mathrm{RH}\right.$ 65\%) [23], before staking twice (Cartigliano PAL 160 leather staking machine, Cartigliano, Bassano, Italy) on the lowest setting. The strength/mechanical properties of the trial leather samples were investigated using British standards: softness [24], grain strength [25], tear strength of leather [26], tensile strength, and percentage elongation at break [27]. To physically determine the extent of penetration of fatliquors in the test pieces, the Sudan (IV) test was carried out: Thin cross-sections $(50 \mu \mathrm{m})$ of the leather samples were cut with a Leica 1850 cryostat microtome (Leica, Wetzler, Germany) (set at $-20^{\circ} \mathrm{C}$ ). Cross-sections of the experimental and controlled samples were gold-coated using a gold sputter coater (Quorom Technologies, Laughton, UK). Their morphology was further examined using a Hitachi S-3000 N scanning electron microscope, SEM (Hitachi, Maidenhead, UK).

\section{Results and discussion}

\subsection{Fatty acid composition}

The fatty acid composition of the S. indicum oil as found in Table 2 revealed the long-chain fatty acids present in the oil. The studied oil was observed to have a higher percentage of unsaturated than saturated fatty acids. This suggests that the $S$. indicum oil acid methylated ester molecule is rich in double bonds which are reactive groups available for the sulfonation reaction [16, 28].

The high content of unsaturated fatty acids gave rise to a high iodine value of $107 \mathrm{~g} \mathrm{I}_{2} / 100 \mathrm{~g}$ as shown in Table 3.

\subsection{Sulfonation reaction process}

The sulfonation reaction and side reaction of the $S$. indicum oil is shown in Schemes 1 and 2. 
Table 1 Fatliquoring Process for Shoe Upper Leather Manufacture

\begin{tabular}{|c|c|c|c|c|c|}
\hline Process & $\%(\mathrm{~m} / \mathrm{m})$ & Chemical & $\mathrm{T}\left({ }^{\circ} \mathrm{C}\right)$ & Time $(\min )$ & Comments \\
\hline \multirow[t]{2}{*}{ Wet Back } & 300 & Water & 30 & & \\
\hline & 0.2 & Surfactant & & 20 & \\
\hline \multicolumn{6}{|l|}{ Drain } \\
\hline Neutralize & 100 & Water & 35 & & - \\
\hline \multirow[t]{2}{*}{ Add } & 1 & Sodium formate & & 5 & \\
\hline & 0.25 & Sodium bicarbonate & & 30 & $\begin{array}{l}\mathrm{pH}=4.3 \\
\text { Bromo-cresol green cross-section = yellow/green }\end{array}$ \\
\hline \multicolumn{6}{|l|}{ Drain } \\
\hline Wash & 200 & Water & 35 & 5 & \\
\hline \multicolumn{6}{|l|}{ Drain } \\
\hline Retan/Fat & 100 & Water & 30 & & \\
\hline \multirow[t]{4}{*}{ Add } & 6 & Replacement syntan & & 15 & \\
\hline & 4 & Vegetable tannin & & 30 & $\mathrm{pH}=4.62$ \\
\hline & 20 & Water & 35 & & \\
\hline & 3 & Acrylic resin & & 30 & $\mathrm{pH}=5.31$ \\
\hline \multicolumn{6}{|l|}{ Drain } \\
\hline Wash & 200 & Water & 50 & 5 & \\
\hline \multicolumn{6}{|l|}{ Drain } \\
\hline Dye/Fat & 100 & Water & 50 & & \\
\hline \multirow[t]{2}{*}{ Add } & 2 & Dye & & 10 & Paste if necessary \\
\hline & 6 & Fatliquor (1:3) & & 40 & Run longer if needed \\
\hline Fix add & 1 & Formic acid $(1: 10)$ & & 20 & $\mathrm{pH}=3.48$ \\
\hline \multicolumn{6}{|c|}{ Drain, wash $X_{2}$, horse up } \\
\hline
\end{tabular}

The sodium salt produced alongside the sulfonated product was filtered off using vacuum filtration to free the resulting sulfonated oil from inorganic salts as depicted in Table 3. The absence of these inorganic salts evidenced by the percent ash result is also reflected in the observed stability of a $10 \%$ solution of sulfonated sesame oil (Table 3). The FTIR and NMR spectra of sulfonated sesame oil, also confirm the presence of $\mathrm{C}-\mathrm{O}-\mathrm{S}$ bond and $\mathrm{C}-\mathrm{S}$ bonds obtained in schemes 1 and 2 respectively.

Table 2 Fatty acid profile of S. indicum oil

\begin{tabular}{ll}
\hline Fatty acid & Percentage composition \% \\
\hline Palmitic C16:0 & 14.29 \\
Stearic C18:0 & 9.60 \\
Oleic C18:1 & 46.84 \\
Linoleic C18:2 & 23.97 \\
EUnsaturated Fatty acids & 70.81 \\
ESaturated Fatty acids & 24.89 \\
Others & 5.30 \\
\hline
\end{tabular}

Table 3 Physicochemical properties of unsulfonated and sulfonated S. indicum oil

\begin{tabular}{|c|c|c|}
\hline Parameter & Unsulfonated & Sulfonated \\
\hline Colour & Golden yellow & Wine red \\
\hline Percentage yield (\%) & 54.7 & 75.4 \\
\hline Specific gravity $\left(\mathrm{g} / \mathrm{cm}^{3}\right)\left(\right.$ at $\left.20^{\circ} \mathrm{C}\right)$ & 0.923 & 0.984 \\
\hline $\mathrm{pH}$ of $10 \%$ emulsion & - & 7.37 \\
\hline Colour of $10 \%$ solution & - & Amber \\
\hline Appearance of $10 \%$ solution & - & Very Translucent \\
\hline Stability of $10 \%$ solution & - & Stable $>24 \mathrm{~h}$ \\
\hline Melting point $\left({ }^{\circ} \mathrm{C}\right)$ & -6.21 & 7.21 \\
\hline Acid value (mg KOH/g) & 2.13 & 1.84 \\
\hline Free fatty acid (as oleic acid) & 1.07 & 0.92 \\
\hline lodine value (g iodine/100 g) & 107 & 19 \\
\hline Saponification value $(\mathrm{mg} \mathrm{KOH/g})$ & 192 & 181 \\
\hline$\% \mathrm{SO}_{3}$ & - & 6.62 \\
\hline$\%$ Ash & - & Trace \\
\hline
\end{tabular}




$$
\mathrm{R} \curvearrowright \mathrm{R}^{\prime}+\mathrm{H}_{2} \mathrm{SO}_{4} \stackrel{20^{\circ} \mathrm{C}}{\longrightarrow} \overbrace{\mathrm{OSO}_{3} \mathrm{H}}^{\mathrm{R}^{\prime}} \underset{\mathrm{NaOH} / \mathrm{CH}_{3} \mathrm{OH}}{\stackrel{\mathrm{CH}_{3} \mathrm{CH}_{2} \mathrm{OH}}{\longrightarrow}} \overbrace{\mathrm{OSO}_{3} \mathrm{Na}}^{\mathrm{R}^{\prime}}+\mathrm{Na}_{2} \mathrm{SO}_{4}
$$

Scheme 1 Sulfonation of $S$. indicum oil to produce sulfated (sulfonated) oil

$$
\mathrm{R}^{\curvearrowright} \mathrm{R}^{\prime}+\mathrm{H}_{2} \mathrm{SO}_{4} \stackrel{20^{\circ} \mathrm{C}}{\longrightarrow} \overbrace{\mathrm{SO}_{3} \mathrm{H}}^{\mathrm{R}^{\prime}} \underset{{\mathrm{NaOH} / \mathrm{CH}_{3} \mathrm{OH}}_{\text {Sulfonated oil (true sulfonates) }}^{\mathrm{OH}}}{\stackrel{\mathrm{CH}_{3} \mathrm{CH}_{2} \mathrm{OH}}{\mathrm{NaO}} \overbrace{\mathrm{SO}_{3} \mathrm{Na}}^{\mathrm{R}^{\prime}}+\mathrm{Na}_{2} \mathrm{SO}_{4}}
$$

Scheme 2 Side reaction of the sulfonation of $S$. indicum oil

\subsection{Physiochemical properties of the oil}

Table 3 shows the physicochemical properties of the studied sulfonated and unsulfonated S. indicum oil. The colour and specific gravity of sesame oil are similar to what is obtainable in most vegetable oils [29]. Having a high percentage of oil yields (54\%), sesame seed has great potential as an industrial crop. The trace amounts of \% Ash found in the modified oil (Table 3) is an indication that the oil is free from inorganic salts. It was also observed from the DSC results in Fig. 1 that the melting point of the $S$. indicum oil increases as the oil is subjected to sulfonation. Since unsaturated fatty acids have a lower melting point than saturated fatty acids [30], the increase in melting point from -6.21 to $7.21{ }^{\circ} \mathrm{C}$ as seen in Table 3 is a confirmation that the $\mathrm{C}=\mathrm{C}$ in the starting unmodified oil (unsulfonated $S$. indicum oil), has been used up. The unsulfonated $S$. indicum oil was observed to have an iodine value of 107; this reveals the presence of high unsaturation in the fatty acid molecule of the oil. This observation is in agreement with the GC-MS results. After sulfonation, the unsaturation degree of the sulfonated oil experienced a drastic decrease in iodine value from 107 to 19 , signifying that the double bonds were used up during the sulfonation reaction. The high percentage of $\mathrm{SO}_{3}(>6.5)$ observed in the synthesized sulfonated S. indicum oil (Table 3 ) is an indication that the oil would have a deep penetration when used in leather fatliquoring [3].

\subsection{Structural analysis}

\subsubsection{FT-IR spectra}

The FT-IR spectra of $S$. indicum oil before sulfonation (blue), and after sulfonation (red) are shown in Fig. 2. It further describes the various peak positions and functional groups in both oil samples. The spectra comparison revealed that characteristic broadband appeared at $\sim 3430 \mathrm{~cm}^{-1}$ as a result of the $\mathrm{OH}$ stretching vibration possibly from the traces of alcohol used in the formation of the sulfonated product. The absorption band at $\sim 3009 \mathrm{~cm}^{-1}$ which represents the unsaturation moiety in the fatty acid disappeared after sulfonation. This disappearance supports the low iodine value result observed in the sulfonated product (Table 3). A band at $\sim 1198 \mathrm{~cm}^{-1}$ appeared after sulfonation which represents the $\mathrm{S}=\mathrm{O}$ stretching frequency (also confirmed by the $\mathrm{OSO}_{3}$ results in Table 3. Another band at $\sim 1049 \mathrm{~cm}^{-1}$ representing the $\mathrm{S}=\mathrm{O}$ asymmetric frequency of the sulfonate group was also observed.

The analytical evaluation of the spectra is shown in Table 4. The absorption peaks are consistent with the reports of the previous studies [3, 31].

\subsection{NMR spectral characterisation 3.5. ${ }^{1} \mathrm{H}$ NMR results}

Figure 3 shows the ${ }^{1} \mathrm{H}$ NMR spectra of unsulfonated sesame oil and sulfonated sesame oil.

The ${ }^{1} \mathrm{H}$ NMR spectrum of the unsulfonated sesame oil which was observed between nine to ten showing different signals of significant intensity is comparable with most vegetable oils $[32,33]$. The peaks at $0.87-$ $0.89 \mathrm{ppm}$ in Fig. 3(a \& b) are due to the proton of the terminal methyl groups [33]. The striking difference between the ${ }^{1} \mathrm{H}$ NMR spectra of the unsulfonated oil and sulfonated oil is the disappearance of the multiplet olefinic protons at $\delta 5.30 \mathrm{ppm}$ attached to the $\mathrm{C}=\mathrm{C}$ double bond in the spectrum (Fig. 3a), and the appearance of the newly formed protons $(\mathrm{H}$ $\mathrm{C}-\mathrm{S}$ and $\mathrm{H}-\mathrm{C}-\mathrm{O})$ in the sulfonated oil spectrum at $\delta$ 3.5 and $3.75 \mathrm{ppm}$ (Fig. 3b). The minor deshielding observed for these protons (Fig. 3a) relative to the rest of the protons in the spectrum in Fig. $3 \mathrm{~b}$ is obtained 


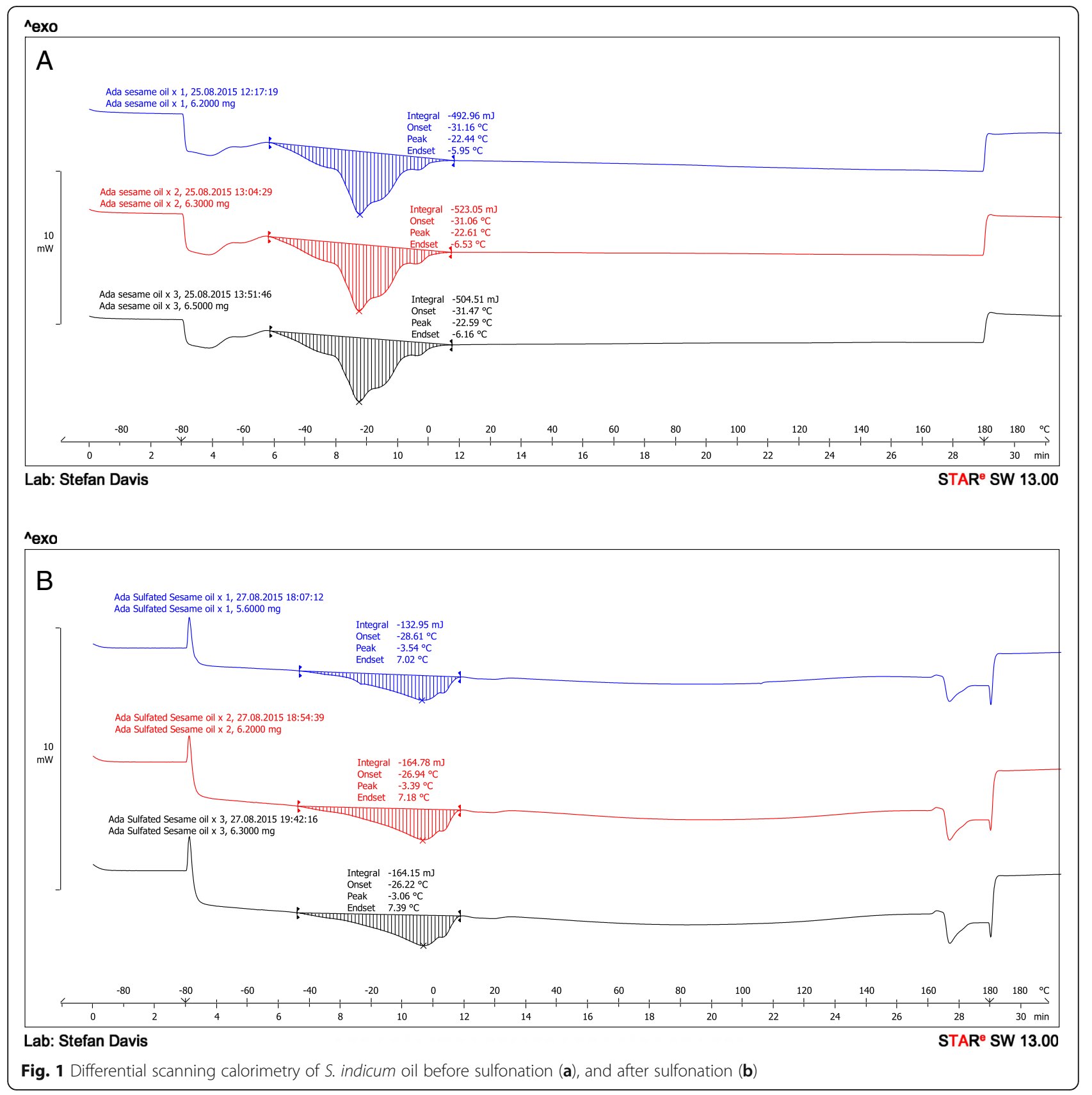

as a result of the inductive effect of the electronegative sulfur and oxygen atoms. The proton NMR for the analyzed samples is evaluated in Table 5.

\subsection{2 ${ }^{13} \mathrm{C} \mathrm{NMR}$ results}

The ${ }^{13} \mathrm{C}$ NMR spectra of the unsulfonated sesame oil and sulfonated sesame oil are depicted in Fig. 4. The ${ }^{13} \mathrm{C}$ NMR spectrum of the unsulfonated oil (Fig. 4a) can be grouped into four spectral regions, namely: The aliphatic carbons ranging from 14.07$34.19 \mathrm{ppm}$; the glycerol carbons which ranges from
62.10-68.89 ppm; the unsaturated carbons which range from $127.89-130.21 \mathrm{ppm}$ and, the carbonyl carbon ranging from $172.83-173.28 \mathrm{ppm}$ [33]. The methyl group at the end of the acyl chains in the glyceride moiety is seen in both spectra (Fig. 4a \& b) at around $14.1 \mathrm{ppm}$. The ${ }^{13} \mathrm{C}$ NMR spectrum of the sulfonated oil (Fig. 4b) can be differentiated from unsulfonated oil by the complete disappearance of the unsaturated carbons (127.89-130.21 ppm) when compared with the starting unsulfonated sesame oil (Fig. 4a). The disappearance of these $\mathrm{sp}^{2}$ carbon 


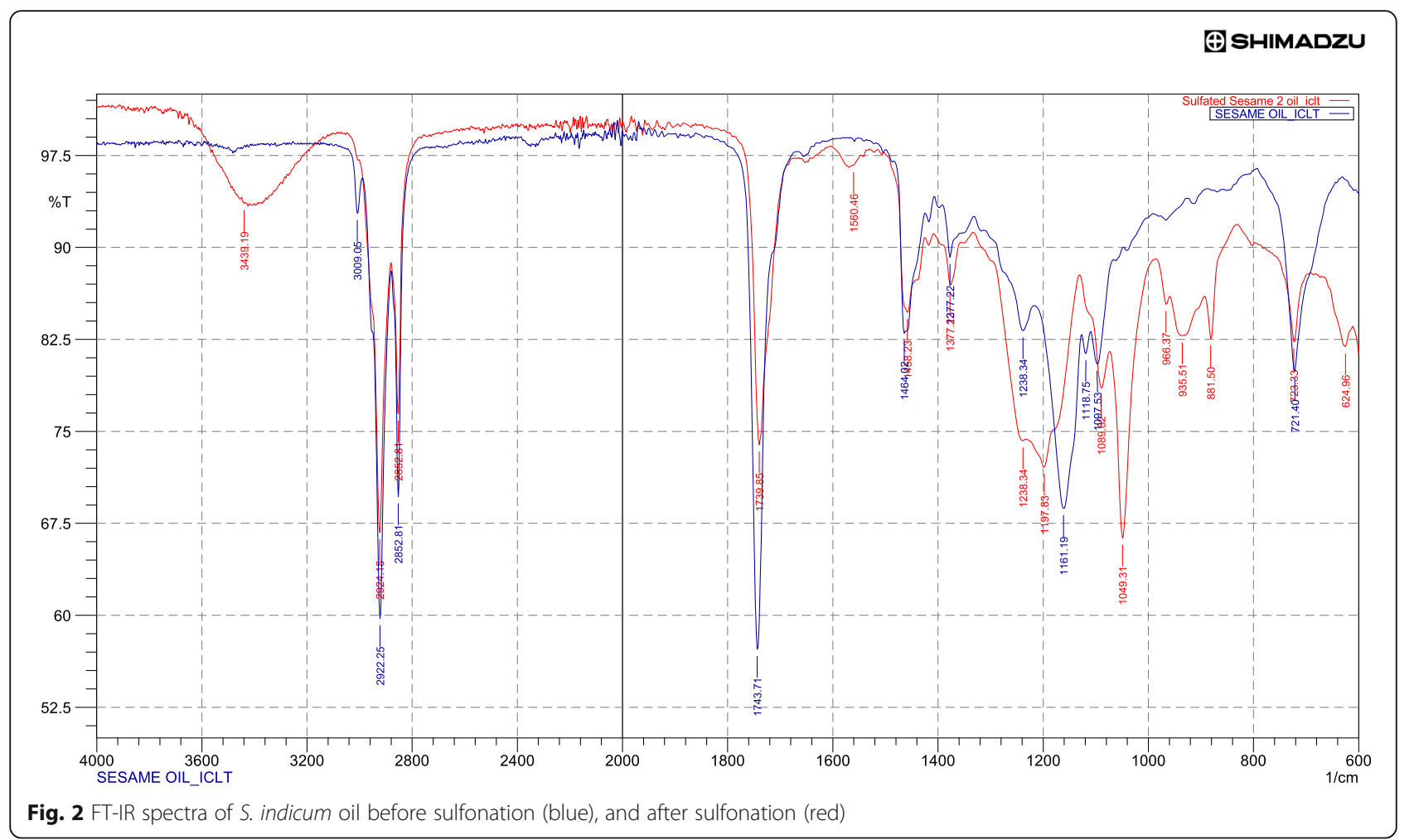

signals took place on sulfonation and is an indication that the double bonds have been used up [16]. This observation further explains the reduction of the iodine value of the starting oil on sulfonation. New signals at $51.45 \mathrm{ppm}$ and $72.28 \mathrm{ppm}$ ascribed to the $\mathrm{sp}^{3}$ hybridised carbons (C-S and $\mathrm{C}-\mathrm{O})$ were also formed after the sulfonation reaction. The inductive effect of the sulfur and oxygen atoms also brought about a slight deshielding position of these signals.

\subsection{3 ${ }^{13} \mathrm{C}$ NMR DEPT results}

Figure 5 shows the ${ }^{13} \mathrm{C}$ NMR DEPT spectra of the studied unsulfonated sesame oil and sulfonated sesame oil. The ${ }^{13} \mathrm{C}$ NMR DEPT spectra appeared to be similar to the ${ }^{13} \mathrm{C}$ NMR spectra. However, it further revealed the presence of $\mathrm{C}-\mathrm{S}$ and $\mathrm{C}-\mathrm{O}$ groups in the sulfonated oil. The chemical shift $\delta$ at $14 \mathrm{ppm}$, belonging to the terminal $\mathrm{CH}_{3}$ was conspicuously observed to be phased down in Fig. 5(a \& b). Also

Table 4 Evaluation of the FT-IR Spectra

\begin{tabular}{|c|c|c|c|}
\hline \multicolumn{2}{|c|}{ Frequency $\mathrm{cm}^{-1}$} & \multirow[t]{2}{*}{ Assignment } & \multirow[t]{2}{*}{ Comments } \\
\hline $\begin{array}{l}\text { Unsulfonated } \\
\text { Oil }\end{array}$ & $\begin{array}{l}\text { Sulfonated } \\
\text { Oil }\end{array}$ & & \\
\hline- & 3430 & $\mathrm{O}-\mathrm{H}$ & The traces of alcohol used in the formation of the sulfonated product. \\
\hline 3009 & - & $\mathrm{C}-\mathrm{H}$ & Stretching vibration of the cis-double bond $(=\mathrm{CH})$. \\
\hline 2922,2853 & 2924,2853 & $\mathrm{C}-\mathrm{H}$ & Symmetric and asymmetric stretching vibration of the $\mathrm{CH}_{2}$ group. \\
\hline 1744 & 1740 & $\mathrm{C}-\mathrm{O}$ & Stretching frequency of Ester carbonyl functional group in the triglyceride. \\
\hline 1464 & 1468 & $\mathrm{C}-\mathrm{H}$ & Bending vibrations of the $\mathrm{CH}_{2}$ and $\mathrm{CH}_{3}$ aliphatic groups. \\
\hline 1377 & 1377 & $\mathrm{C}-\mathrm{H}$ & Bending vibrations of $\mathrm{CH}_{2}$ groups. \\
\hline 1238 & 1238 & $\mathrm{C}-\mathrm{O}$ & Stretching vibration of the $\mathrm{C}-\mathrm{O}$ ester groups \\
\hline- & 1198 & $\mathrm{~S}=\mathrm{O}$ & Stretching of both sulfate and sulfonate groups. \\
\hline- & 1049 & $\mathrm{~S}=\mathrm{O}$ & Asymmetric stretching frequency of the sulfate and sulfonate groups. \\
\hline 721 & 723 & $\mathrm{C}-\mathrm{C}$ & Overlapping of $\mathrm{CH}_{2}$ rocking vibration and the out of plane vibration of cis- disubstituted olefins. \\
\hline
\end{tabular}




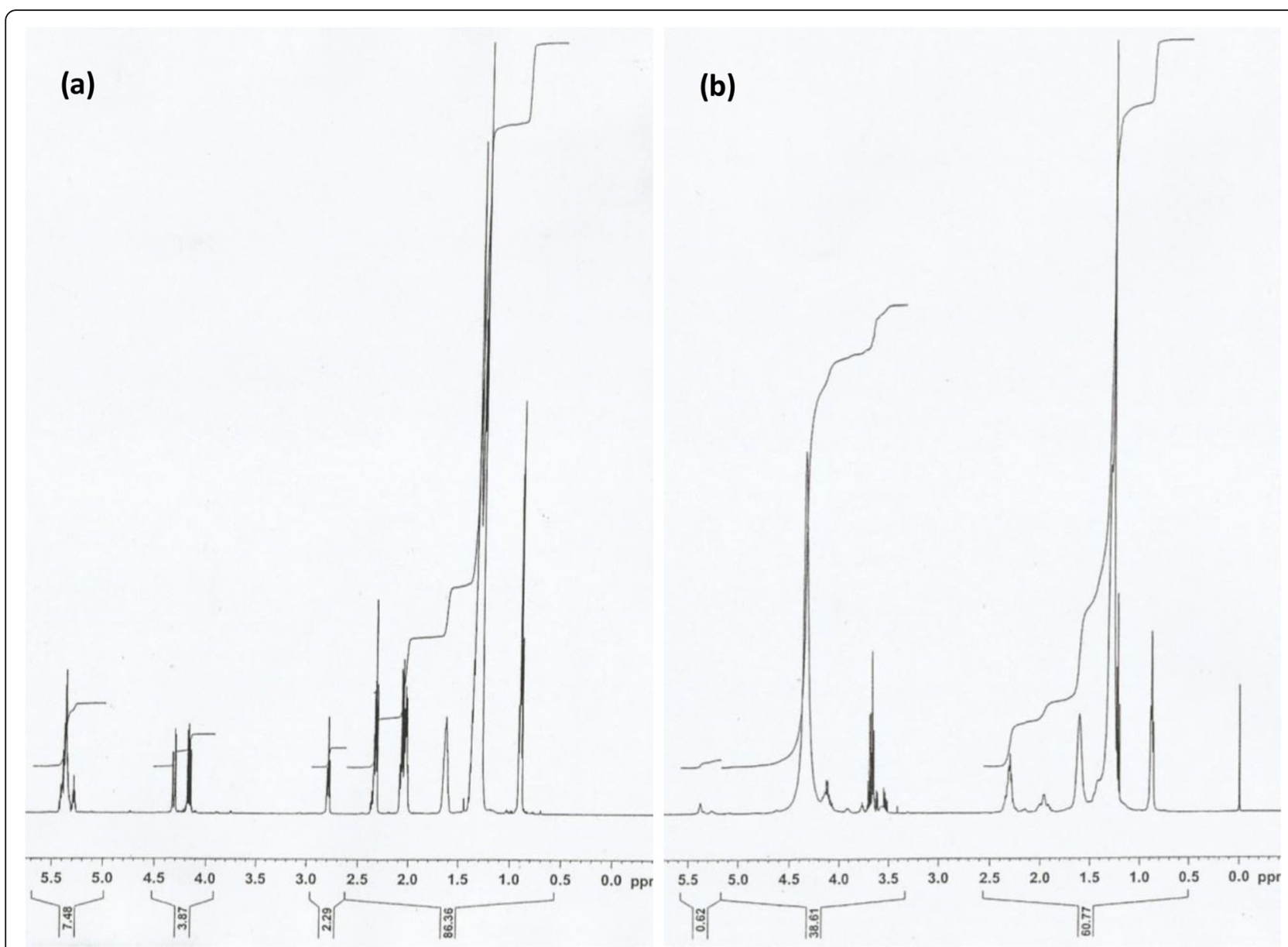

Fig. $3^{1} \mathrm{H}$ NMR spectra of $\mathbf{a}$ unsulfonated $S$. indicum oil $\mathbf{b}$ sulfonated $S$. indicum oil

seen phased down, is the $\mathrm{C}-\mathrm{H}-\mathrm{O}$ of the glycerol backbone at $68 \mathrm{ppm}$. The $-\left(\mathrm{CH}_{2}\right)_{2}-$ moiety was seen at various positions ranging from $\delta 22.4 \mathrm{ppm}-34$ ppm in an upward direction (Fig. 5(a and b)).

The evidence of the sulfonation reaction that was carried out on the sesame oil can be seen with the disappearance of the $\mathrm{HC}=\mathrm{CH}$ (Fig. 5b) which was initially observed phased down in the unsulfonated sesame oil (Fig. 5a) between the ranges of $\delta 127.89$ $130.31 \mathrm{ppm}$. The sulfonation reaction (schemes 1 and 2) was confirmed with the formation of the C-O-S bond $(\delta 72.31 \mathrm{ppm})$ and $\mathrm{C}-\mathrm{S}$ bonds $(\delta 51.45 \mathrm{ppm})$ in

Table $5{ }^{1} \mathrm{H}$ NMR evaluation of unsulfonated and sulfonated oils

\begin{tabular}{|c|c|c|}
\hline \multirow{2}{*}{$\begin{array}{l}\text { Chemical } \\
\text { shift } \delta \\
\text { (ppm) }\end{array}$} & \multicolumn{2}{|l|}{ Peak Assignment } \\
\hline & Unsulfonated oil & Sulfonated oil \\
\hline $0.8-0.9$ & Protons of the terminal $\mathrm{CH}_{3}$ group & Protons of the terminal $\mathrm{CH}_{3}$ group \\
\hline $1.2-1.4$ & $\mathrm{CH}_{2}$ protons in allylic chain & $\mathrm{CH}_{2}$ protons in allylic chain \\
\hline $1.6-1.7$ & $\begin{array}{l}\text { Protons of }-\mathrm{CH}_{2} \text { groups attached next to the above terminal } \\
\text { methyl group }\end{array}$ & $\begin{array}{l}\text { Protons of }-\mathrm{CH}_{2} \text { groups attached next to the above terminal } \\
\text { methyl group }\end{array}$ \\
\hline $2.0-2.6$ & Allylic protons of $-\mathrm{CH}_{2}$ group & Allylic protons of $-\mathrm{CH}_{2}$ group \\
\hline $3.5-3.75$ & Not observed & Newly formed protons (H-C-S and $\mathrm{H}-\mathrm{C}-\mathrm{O}$ ) \\
\hline $4.15-4.30$ & $\mathrm{CH}_{2}$ protons of the glyceride moiety & $\mathrm{CH}_{2}$ protons of the glyceride moiety \\
\hline $5.2-5.4$ & protons of the $-\mathrm{CH}=\mathrm{CH}-$ moiety. & Not observed \\
\hline
\end{tabular}


(a)

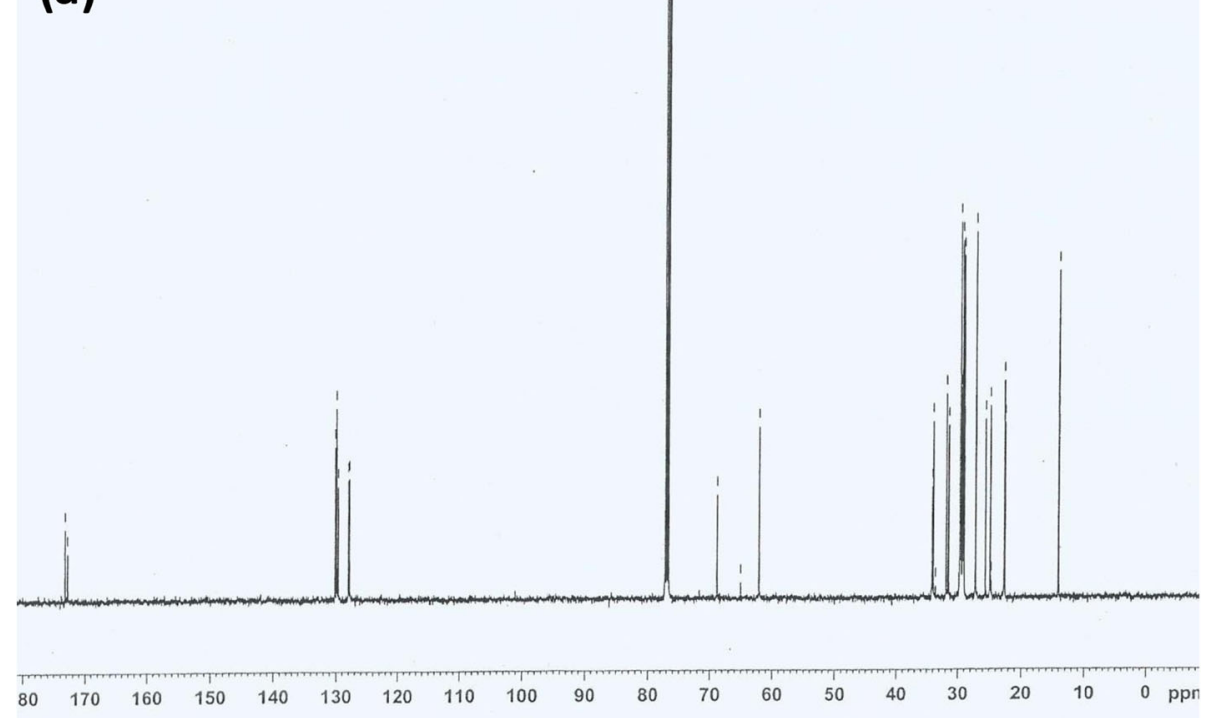

(b)

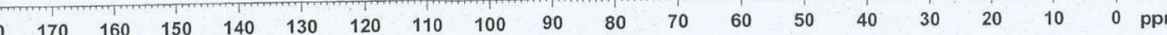

Fig. $4{ }^{13} \mathrm{C}$ NMR spectra of a unsulfonated $S$. indicum oil $\mathbf{b}$ sulfonated S. indicum oil

the spectrum of the studied sulfonated sesame oil (Fig. 5b).

\subsection{Stability of the $10 \%$ Fatliquor emulsions}

The results of the stability of the $10 \%$ fatliquor emulsions are shown in Table 6. It was observed that the sulfonated $S$. indicum has good emulsion stability in hard water, deliming, and pickling solutions. Good emulsion stability is essential for adequate penetration of the fatliquor into the leather fibres. It was however unstable in formic acid. Immediately a stable emulsion particle hits the fibre structure, the sulfo fraction interacts with it, causing the emulsion to lose its emulsifier and the neutral oil will be deposited. This occurs during leather fixation [1]. 


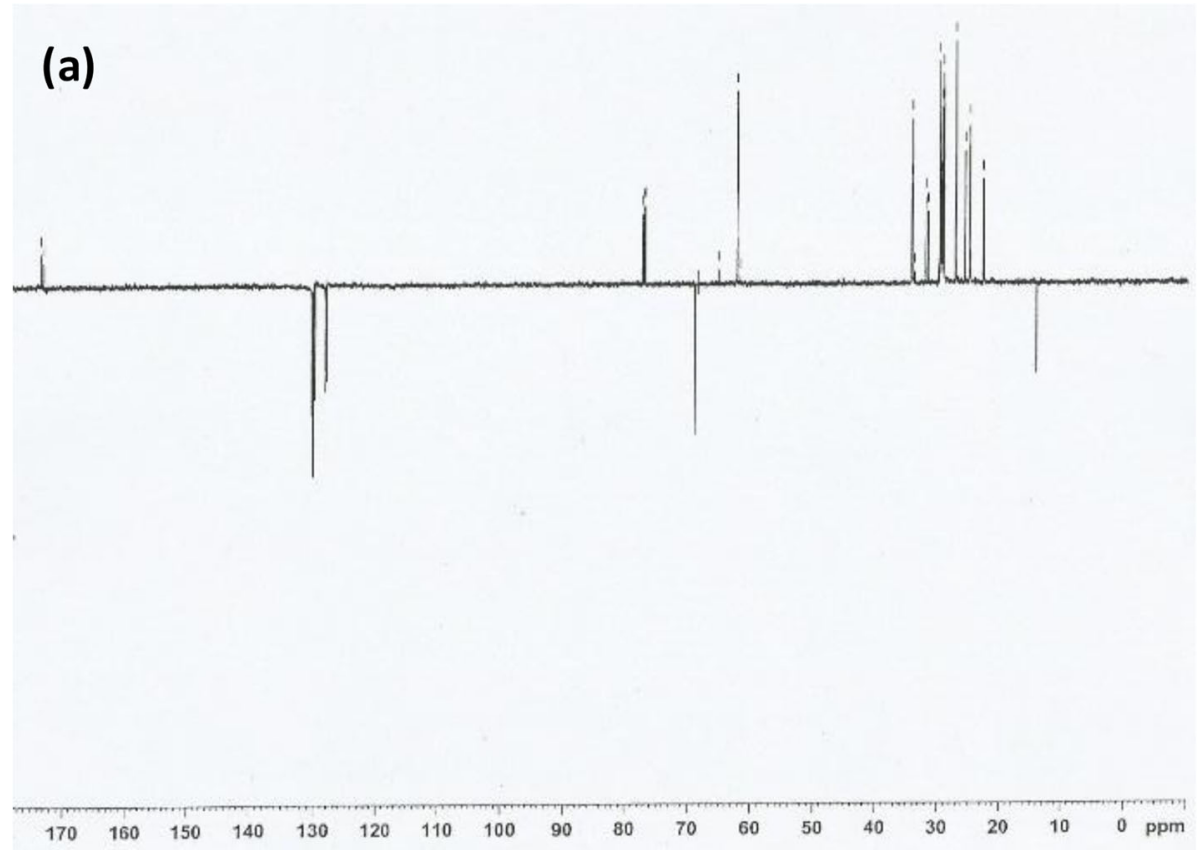

(b)

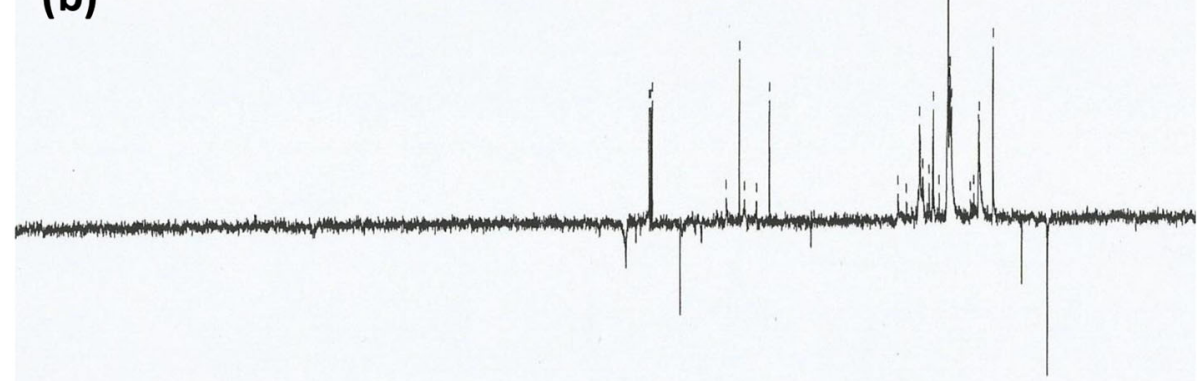

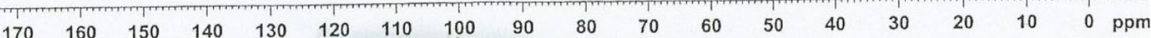

Fig. $5^{13} \mathrm{C}$ NMR DEPT spectra of a unsulfonated S. indicum oil b sulfonated S. indicum oil

Table 6 Stability of 10\% Sulfonated S. indicum fatliquor towards pickle liquor, tan liquor and hard water

\section{Solution added}

$5 \%$ Basic chromium sulphate (tan liquor)

$5 \% \mathrm{MgSO}_{4}$ (hard water)

$5 \% \mathrm{NaCl}$ (found in pickle liquor)

$5 \%$ Formic acid
Stability Status

Stable $(\sim 1$ h)

Stable

Stable

Unstable

\subsection{Mechanical properties results}

\subsubsection{Softness test results}

The softness testing of the leather shoe upper test pieces carried out using the softness testing machine ST300 (25 mm aperture), showed no significant differences in the test pieces as the leather processed with the commercial sulfated oil, TRUPON DXV (PC) and that processed with sulfonated Sesame oil (SSO) had 
Table 7 Tensile Strength, Elongation at Break and Double Edge Tear Results

\begin{tabular}{llll}
\hline Properties & & PC & SSO \\
\hline Tensile strength $\left(\mathbf{N} / \mathbf{m m}^{2}\right)$ & Parallel & $15.50 \pm 0.03$ & $14.10 \pm 0.35$ \\
Mean Tensile strength $\left(\mathbf{N} / \mathbf{m m}^{2}\right)$ & Perpendicular & $13.03 \pm 2.19$ & $13.44 \pm 0.39$ \\
Elongation at break (\%) & Parallel & 14.27 & 13.77 \\
& Perpendicular & $34.72 \pm 1.21$ & $48.00 \pm 2.34$ \\
Average Elongation at break (\%) & & $41.38 \pm 0.59$ & $60.54 \pm 0.66$ \\
Tear Load (Double edge Tear) (N) & Parallel & 38.06 & 54.28 \\
& Perpendicular & $42.32 \pm 2.53$ & $61.43 \pm 1.64$ \\
Average Tear Load (Double edge Tear) $\mathbf{( N )}$ & & $58.89 \pm 1.93$ & $58.79 \pm 4.18$ \\
\hline
\end{tabular}

average values of $25.2 \pm 0.54$ and $25.0 \pm 0.65$ respectively, an indication that one could be substituted for another.

\subsubsection{Tensile strength and elongation at break results}

The tensile strength, elongation at break, and double edge tear results are shown in Table 7 . The average tensile strength result of PC shows comparable values with SSO. Average elongation at break which is one of the important properties that determines the quality of a leather shoe upper was seen to be higher for SSO compared to PC. This reveals that the leather sample, SSO is more elastic than PC. This observation is clear evidence that the use of sulfonated sesame oil for the processing of goatskin brought about more flexible leather than that processed with commercial sulfated oil.

The double edge tear strength of the leather shoe upper analysis shows that the leather treated with sulfonated oil had higher average tear strength $(60.1 \mathrm{~N})$

Table 8 Strength of Grain Surface of Leather Test Pieces

\begin{tabular}{lll}
\hline Properties & PC & SSO \\
\hline Grain crack strength (N) & 400 & 400 \\
& 380 & 380 \\
Average Grain crack strength (N) & 390 & 390 \\
Distention at grain crack (mm) & 9.01 & 9.02 \\
& 8.95 & 9.09 \\
Average Distention at grain crack (mm) & 9.00 & 9.06 \\
Ball Burst strength(N) & 420 & 400 \\
& 390 & 380 \\
Average Ball Burst Strength (N) & 405 & 390 \\
Distention at burst (mm) & 9.58 & 9.02 \\
& 9.01 & 9.09 \\
Average Distention Burst (mm) & 9.30 & 9.06 \\
\hline
\end{tabular}

than the commercial sulfated oil-treated leather (50.61 $\mathrm{N})$. This result also supports the use of sulfonated sesame oil for the processing of goatskin as its application on the studied goatskin leather brought about more flexible leather than that processed with commercial sulfated oil.

\subsubsection{Strength of grain surface of Leather results}

Table 8 shows the result of the strength of grain surface analysis that was carried out on the leather test pieces (Ball burst test). The leather shoe upper should possess high flexibility to prevent the appearance of cracks and tears. The ball burst test determines the strength of leather grain and the capacity of the shoe upper leather to resist the increasing force which often leads to cracking or bursting. The result reveals that the average strength at grain crack and average strength at grain burst of the leather samples (PC and SSO) had very close results with negligible differences.

\subsubsection{Sudan IV stain results}

Staining renders visible components within the section that would not be seen easily. The soaking of leather sections in Sudan IV dye which is specific for fats and oils, reveals the presence of fats and oil in the leather sections. This serves as proof of the extent of penetration of the fatliquors in the leather sections. It further explains the extent of the lubrication of the leather fibres. Fatliquored leather sections will have red stains from the Sudan IV dye in areas lubricated with fatliquor. Unfatliquored leather does not have that red stain when exposed to Sudan IV dye. Figure 6 shows Sudan (IV) stain test analysis of the leather test pieces, PC, and SSO. The result showed that the fatliquor produced penetrated deeply into the leather and not on the surface. The lubrication of the trial leather test sample processed 


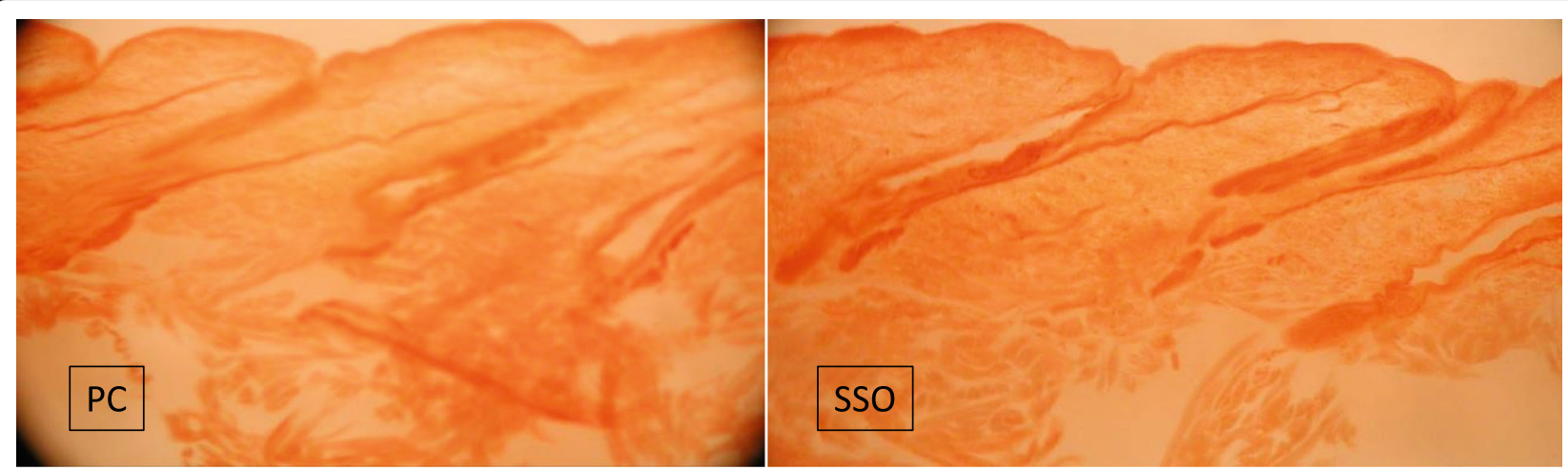

Fig. 6 Sudan (IV) stain test results for the leather test pieces, PC, and SSO

with sulfonated sesame oil, labeled SSO, could be compared to the leather sample which was processed with the PC (positive control), commercial sulfated fatliquor, TRUPON DXV commonly used in most Nigerian tanneries. Sudan IV stain test results show that these experimental leathers, PC, and SSO had comparable lubrication, signifying a high level of penetration within the leather fibres. This result is in agreement with their similar mechanical properties.

\subsubsection{Scanning Electron microscopy results}

Figure 7 shows the scanning electron microscopy of leather bundles of PC and SSO. The leather sample processed with commercial sulfated fatliquor, PC, and the leather which was processed with the as-synthesized sulfonated sesame oil, SSO all exhibited opened up structures on drying. This further indicates that the leather shoe upper fibres which did not stick together because of the good lubrication can comfortably slide over one another and could be used in the manufacture of shoes.

\section{Conclusion and recommendation}

The oil of sesame seed, an annual crop that is highly underutilized in Nigeria was evaluated for its potential use in the leather industry. This study successfully carried out the sulfonation of Sesamum indicum oil via a process that does not involve washing of excess sulfuric acid with aqueous solutions. The success of the sulfonation of the vegetable oil has been shown in the FTIR, ${ }^{1} \mathrm{H}$ NMR, ${ }^{13} \mathrm{C}$ NMR, and ${ }^{13} \mathrm{C}$ NMR DEPT analysis results. The sulfonated oil which was tested for its fatliquoring ability in comparison with a commercial sulfated fatliquor commonly used in many Nigerian leather industries proved to produce leather shoe upper with excellent mechanical properties. The findings of this study reveal that sulfonated sesame oil could be used as a cheaper and effective alternative leather fatliquor for the manufacture of leather
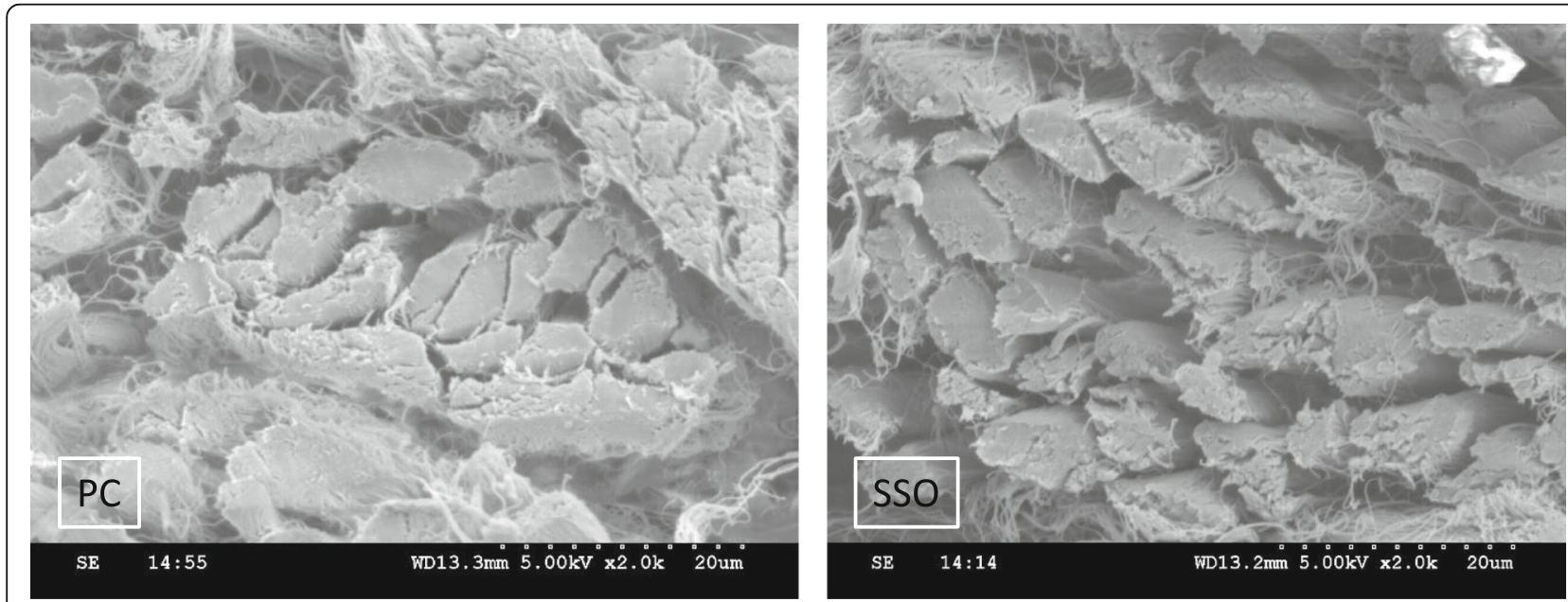

Fig. 7 Scanning electron microscopy results for the leather test pieces, PC, and SSO. (Magnification: X 2000) 
shoe upper. Therefore, it is comparatively preferable to synthesize fatliquor locally to save the expenditure on imports. This, therefore, is an import substitution for fatliquors in Nigeria.

\section{Supplementary Information}

The online version contains supplementary material available at https://doi. org/10.1186/s42825-021-00053-4.

\section{Additional file 1.}

\section{Acknowledgments}

The authors thank the staff of the Institute for Creative Leather Technologies (ICLT), University of Northampton, (UoN) Northampton, United Kingdom, for their support in the laboratory and tannery.

\section{Authors' contributions}

AN conceived and designed the experiments, contributed reagents, and materials, performed the experiments, analyzed the data, and interpreted the data. AN wrote the paper while other authors made their input. PU conceived the idea of the experiment, contributed reagents, and supervised the research. $\mathrm{HI}$ analyzed and interpreted the data. All authors provided critical feedback and helped shape the research, analysis, and manuscript. The author(s) read and approved the final manuscript.

\section{Funding}

This research did not receive any specific grant from funding agencies in the public, commercial, or not-for-profit sectors.

\section{Availability of data and materials}

Detailed data for the GC-MS analysis is included as supplementary material.

\section{Declaration}

\section{Competing interests}

The authors declare that they have no competing interests.

\section{Author details}

${ }^{1}$ Department of Chemistry/Biochemistry/Molecular Biology, Alex Ekwueme Federal University Ndufu-Alike Ikwo, P.M.B 1010, Abakaliki, Ebonyi State, Nigeria. ${ }^{2}$ Department of Pure and Industrial Chemistry, University of Nigeria Nsukka, Enugu State 410001, Nigeria. ³ Department of Research Operation, Rubber Research Institute of Nigeria, P.M.B. 1049, Benin-City, Nigeria.

Received: 19 June 2020 Accepted: 28 February 2021

Published online: 15 May 2021

\section{References}

1. Covington AD. Tanning chemistry: the science of leather. Cambridge: Royal Society of Chemistry Publishing; 2011.

2. Megahed MG, EHA N. Ester phosphate of discarded palm oil from potato chip factories as fat-liquoring agent. J Am Sci. 2010;6(12):617-26.

3. Nkwor AN, Ukoha PO, Wise WR, Nwaji NN, Flowers K. Fatty acid profile, and production of Fatliquor from Canarium schweinfurthii Mesocarp oil. Pertanika J Sci Technol. 2019;27(4):2221-43.

4. Ola AM, Habib MA, El Sayed NH. Sulfitation of animal bone fat for use as a Fatliquor. Soc Leather Technol Chem J. 2015;98:205-10.

5. Zarlok J, Smiechowski K, Mucha K, Tecza A. Research on application of flax and soya oil for leather fatliquoring. J Clean Prod. 2014;65:583-9.

6. Daniels RP. Fatliquoring and softening agents. World Leather. 2001;14:68-70.

7. Nkwor AN, Ukoha PO, Wise W, Flowers K. Fatliquoring potentials of sulphonated Hura crepitans L seed oil. Leather Footwear J. 2019;19(2): 99-112.

8. Quadery AH, Uddin T, Azad A, Chowdhury MJ, Deb AK, Hassan N. Fatliquor Preparation from Karanja Seed Oil (Pongamia pinnata L.) and its Application for Leather Processing. IOSR J Appl Chem. 2015;8:54-8.
9. Affiang SD, Ggamde G, Okolo VN, Olabode V, Jekkada JZ. Synthesis of sulphated-fatliquor from neem (Azadirachta indica) seed oil for leather tannage. Am J Eng Res. 2018;7(4):215-21.

10. Biabani AR, Pakniyat $H$. Evaluation of seed yield-related characters in sesame (Sesamum indicum L.) using factor and path analysis. Pak J Biol Sci. 2008; 11(8):1157-60.

11. Nzikou JM, Mvoula-tsiéri M, Ndangui CB, Pambou-Tobi NPG, Kimbonguila A, Loumouamou B, Silou TH, Desobry S. Characterization of seeds and oil of sesame (Sesamum indicum L.) and the kinetics of degradation of the oil during heating. Res J Appl Sci, Eng Technol. 2010;2:227-32.

12. Dar AA, Kancharla PK, Chandra K, Sodhi YS, Arumugam N. Assessment of variability in lignan and fatty acid content in the germplasm of Sesamum indicum L. J Food Sci Technol. 2019;56(2):976-86 PubMed PMID: 30906055. Epub 02/04. eng.

13. Redondo-Cuevas L, Castellano G, Torrens F, Raikos V. Revealing the relationship between vegetable oil composition and oxidative stability: A multifactorial approach. J Food Compos Anal. 2018;66:221-9 2018/03/01/.

14. El Riachy M, Hamade A, Ayoub R, Dandachi F, Chalak L. Oil content, fatty acid, and phenolic profiles of some olive varieties growing in Lebanon. Front Nutr. 2019:6(94):1-13.

15. Wei $X$, Zhu X, Yu J, Wang L, Zhang Y, Li D, et al. Identification of sesame genomic variations from genome comparison of landrace and variety. Front Plant Sci. 2016;7(1169):1-12.

16. Nkwor AN, Ukoha PO. Evaluation of the leather fatliquoring potential of sulphonated Afzelia africana aril cap oil. Heliyon. 2020;6(1):e03009.

17. SLTC SfLTaC. SLTC methods. Withernsea: Society of Leather Technologists and Chemists; 1996

18. Adewuyi A, Awolade PO, Oderinde RA. Hura crepitans seed oil: an alternative feedstock for biodiesel production. J Fuels. 2014;2014:8.

19. Waite T. Oils, fats, waxes, and fatliquors. In: Leafe MK, editor. Leather technologists pocket book. UK: Society of Leather Technologists and Chemists Withernsea; 1999. p. 125-48.

20. Nassu RT, Guaraldo Gonçalves LA. Determination of melting point of vegetable oils and fats by differential scanning calorimetry (DSC) technique. Grasas Aceites. 1999:50(1):16-21 Epub 1999-02-28.

21. 2418 B. Leather- Chemical, physical and mechanical and fastness tests: Sampling location. London: British Standards Institution; 2002

22. ICLT SR 15/31 Institute for Creative Leather Technologies. Leather Manufacture: Shoe Upper-Chromium (Non-Compact). Northampton: Institute for Creative Leather Technologies; 2015. p. 1-2.

23. 2419 B. Chemical, physical and mechanical and fastness tests: Conditioning. London: British Standards Institution; 2002.

24. 17235 B. Leather, physical and mechanical tests: Determination of softness. London: British Standards Institution; 2015.

25. BS 3379. Physical and mechanical tests: Determination of distension and strength of surface Leather (Ball Burst method). London: British Standards Institution; 2015

26. $3377-2$ B. Leather. Physical and mechanical tests. Determination of Tear Load Double edge tear. 2011.

27. BS 3376. Leather, physical and mechanical tests: Determination of tensile strength and percentage extension. London: British Standards Institution; 2012.

28. Pathak N, Rai AK, Kumari R, Bhat KV. Value addition in sesame: A perspective on bioactive components for enhancing utility and profitability. Pharmacognosy Rev. 2014;8(16):147-55 PubMed PMID: 25125886. eng.

29. Gunstone FD. The chemistry of oils and fats: sources. In: Composition properties and uses. Oxford: Blackwell Pub Ltd; 2004. p. 100-39.

30. Berg JM, Tymoczko JL, Stryer L. Fatty acids are key constituents of lipids. In: Biochemistry. 5th ed. New York: W H Freeman; 2002. Section 12.2.

31. Alam M, Akram D, Sharmin E, Zafar F, Ahmad S. Vegetable oil-based eco-friendly coating materials: A review article. Arabian J Chem. 2014;7(4):469-79.

32. Guillén María D, Ainhoa R. Monitoring of heat-induced degradation of edible oils by proton NMR. Eur J Lipid Sci Technol. 2008;110(1):52-60.

33. Sega A, Zanardi I, Chiasserini L, Gabbrielli A, Bocci V, Travagli V. Properties of sesame oil by detailed $1 \mathrm{H}$ and 13C NMR assignments before and after ozonation and their correlation with iodine value, peroxide value, and viscosity measurements. Chem Phys Lipids. 2010;163(2):148-56 PubMed PMID: 19900426. Epub 2009/11/11. eng.

\section{Publisher's Note}

Springer Nature remains neutral with regard to jurisdictional claims in published maps and institutional affiliations. 